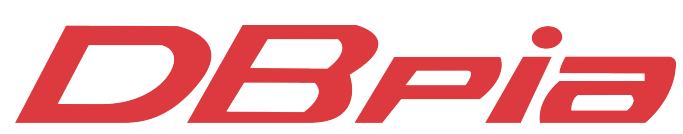

\title{
Motivational Regulation for Learning English Writing Through Zoom in an English- Medium Instruction Context
}

\author{
저자 \\ Jeongyeon Kim, Victoria Kim \\ (Authors) \\ 출처 \\ (Source) \\ 발행처 \\ (Publisher) \\ ENGLISH TEACHING(영어교육) 76(특별), 2021.9, 37-57 (21 pages) \\ ENGLISH TEACHING 76(특별), 2021.9, 37-57 (21 pages) \\ 한국영어교육학회 \\ Korea Association Of Teachers Of English
}

URL

APA Style

이용정보

(Accessed)
http://www.dbpia.co.kr/journal/articleDetail?nodeld=NODE10605101

Jeongyeon Kim, Victoria Kim (2021). Motivational Regulation for Learning English Writing Through Zoom in an English-Medium Instruction Context. ENGLISH TEACHING(영어교육), 76(특별), 37-57.

울산과학기술원

2021/10/13 17:12 (KST)

DBpia에서 제공되는 모든 저작물의 저작권은 원저작자에게 있으며, 누리미디어는 각 저작물의 내용을 보증하거나 책임을 지지 않습니다. 그리고 DBpia에서 제 공되는 저작물은 DBpia와 구독계약을 체결한 기관소속 이용자 혹은 해당 저작물의 개별 구매자가 비영리적으로만 이용할 수 있습니다. 그러므로 이에 위반하여 DBpia에서 제공되는 저작물을 복제, 전송 등의 방법으로 무단 이용하는 경우 관련 법령에 따라 민, 형사상의 책임을 질 수 있습니다.

\section{Copyright Information}

Copyright of all literary works provided by DBpia belongs to the copyright holder(s)and Nurimedia does not guarantee contents of the literary work or assume responsibility for the same. In addition, the literary works provided by DBpia may only be used by the users affiliated to the institutions which executed a subscription agreement with DBpia or the individual purchasers of the literary work(s)for non-commercial purposes. Therefore, any person who illegally uses the literary works provided by DBpia by means of reproduction or transmission shall assume civil and criminal responsibility according to applicable laws and regulations. 


\title{
Motivational Regulation for Learning English Writing Through Zoom in an English-Medium Instruction Context
}

\author{
Jeongyeon Kim and Victoria Kim*
}

\begin{abstract}
Kim, Jeongyeon, \& Kim, Victoria. (2021). Motivational regulation for learning English writing through Zoom in an English-medium instruction context. English Teaching, 76(s1), 37-57.

Due to growing concerns regarding the effectiveness of full-scale online education, this study investigated motivational regulation strategies employed by tertiary-level English as a foreign language (EFL) learners taking a writing course via Zoom. Using a mixed method, this study examined a dataset comprising questionnaire responses of 154 Korean students with two proficiency levels and subsequent semi-structured interviews. Findings showed that the learners with a high English proficiency level utilized the instructor's feedback significantly more than those having a low proficiency level. The high proficiency group also appreciated the Zoom context and the universitywide policy of English-medium instruction (EMI) significantly better than the other group. Finally, correlation analysis revealed significant relationship between the students' uses of motivational regulation strategies and their responses to the contextdependent factors. For example, the strategic choice of instructor feedback was positively related to their perception of EMI. These findings are discussed for effective online EFL writing instruction in the post-pandemic era.
\end{abstract}

Key words: Motivational regulation strategies, Zoom, EFL writing, online learning, English-medium instruction

\footnotetext{
*Corresponding Author: Jeongyeon Kim, Professor, School of Liberal Arts, Ulsan National Institute of Science \& Technology; 50 UNIST-gil, Ulsan 44919, Korea; Email: jkim@unist.ac.kr

Co-author: Victoria Kim, Professor, School of Business Administration, Ulsan National Institute of Science \& Technology
}

Received 9 May 2021; Reviewed 6 July 2021; Accepted 30 August 2021 appropriately cited. 


\section{INTRODUCTION}

Since the outbreak and spread of COVID-19 in early 2020, educational sectors of all levels have experienced a dramatic shift. With the closure of campuses, instructors and students alike have been required to quickly adapt to online stations. This unexpected transition to a full-scale online educational environment has created many unforeseen challenges with growing concerns regarding its effectiveness in teaching and learning. Researchers have now moved beyond the aggregated studies on technology-based online learning. Full-scale online classes conducted in a variety of educational settings are now up for rigorous investigation. According to a recent report by the Korea Education Development Institute (2020), six out of 16 topics related to education problems under the COVID-19 pandemic are highereducation oriented. Those topics-including 'search for future education changes,' 'online class implementation,' 'request for tuition reimbursement,' 'student support program,' 'difficulty in evaluating students,' and 'educational policy makers' effective actions'amount to a demand that educational institutions not only optimize online classes to provide quality education with fair evaluation methods; but they also accelerate reforms and systemize educational resources to respond appropriately to future disaster situations (Marcus, 2020).

Intriguingly, several recent studies on full-scale online learning have revealed mixed results on the effectiveness of online settings in learning processes and outcomes. Park (2020) found that Korean EFL learners experienced a higher level of anxiety in real-time synchronous online classes than asynchronous classes. These synchronous online lectures through Zoom were disfavored mainly due to time constraints. In stark contrast to this finding, Lee and Kim (2020) reported that English-education majors were more satisfied with real-time online than with non-real-time online classes. Similarly, both Jung (2020) and M. Kim (2020) have shown that college EFL learners greatly appreciate online classes and exams for its promotion of learner autonomy as compared with offline classes. These studies illuminate that the online learning context contributes much to learning processes and outcomes, despite apparent limitations in students' interaction with professors and peers.

The success of this virtual learning context has been recurrently associated with learners' autonomous attitude towards learning (Lee \& Kim, 2020; Park, 2020). Learner autonomy is central to self-regulated learning (SRL) theory, which highlights learners' ability to actively initiate, maintain, and increase motivation to learn. Motivational regulation, according to Dörnyei (2001), is an action in which learners optimize knowledge and skills to motivate learning autonomously. L2 researchers (Csizér \& Tankó, 2017; Oxford, 2013) have confirmed its explicit role in teaching and learning second/foreign language (SL/FL). For example, EFL writers frequently become demotivated and should be able to use various strategies to maintain their motivation to complete writing (Tang, 2012; Teng \& Zhang, 
2016). In an EFL writing context, in particular, motivational regulation has been found to be exercised according to learners' proficiency level (Teng, Yuan, \& Sun, 2020). In their examination of motivational regulation strategies used by Chinese learners of EFL writing, the more proficient group was found to use more strategies like self-talk, increased interest, and better emotional control. These studies affirm that teaching L2 writing involves not only how to write, but also how to increase writing motivation (Bruning \& Horn, 2000). Strategies to regulate EFL writing motivation, therefore, should be instructed in a systematic manner (Teng et al., 2020).

SRL-based studies have also disclosed the roles of a learning context in fostering learners' self-regulatory actions (Dörnyei \& Ushioda, 2011; Zhang \& Guo, 2012). Admittedly, L2 learning motivation may vary according to how learners perceive the context (Zhang \& Guo, 2012). Specifically, learners control and maintain their motivation through imminently constructed knowledge of relevant contextual factors, ranging from a language policy at large to an online- or offline- learning setting. The current study adopts this sociocultural perspective regarding motivational regulation learning (Oxford, 2013; Oxford \& Amerstorfer, 2018; Zhang, Thomas, \& Qin, 2019) and focuses on some recent major trends in higher education (HE), such as English-medium instruction and the recent full-scale online learning. Given that these contextually bound factors have posed substantial challenges and created major controversy in Korean HE institutions (e.g., J. Kim, 2011; J. Kim, E. G. Kim, \& Kweon, 2018; Nam, 2011), this study explores the ways in which context-dependent factors (English-medium instruction, online learning, and a native English-speaking instructor) relate to the uses of motivational regulation strategies of Korean EFL writers situated in the new full-fledged online learning environment.

\section{REVIEW OF LITERATURE}

\subsection{Learner Autonomy and Motivational Regulation Strategies}

Research on motivation has highlighted individual learners' contributions to learning and established the link between learner autonomy and motivation. Beginning in the 1990s, L2 researchers have rigorously examined dynamic workings of motivation in various educational contexts (Dörnyei, 2001; Noels, Pelletier, \& Vallerand, 2000; Vandergrift, 2005). In their quantitative study of L2 motivation, Noels and colleagues (2000) showed that perceived freedom of choice and L2 competence are crucial to increasing motivation. They further suggested that, in order to foster sustained learning, students should be convinced that language learning is not only interesting and enjoyable, but also personally important for them. Specifically, they would be willing to invest time and effort, a sign of active 
engagement in learning, according to the Vandergrift's (2005) study of L2 French learning motivation. These L2 learners were found to use metacognitive listening strategies in a selfregulatory manner. Thus, as Zimmerman (2011) explains, this active management provides a channel to learners' successful learning experiences.

In SRL theory, learners' ability to regulate their learning depends on whether they can use cognitive and metacognitive strategies. Framed within Dörnyei's theoretical taxonomy (2001), these strategies include learners' conscious control over their commitment (e.g., to preserve or increase their original goal-directed commitment), metacognition (e.g., monitoring concentration), satiation (e.g., eliminating boredom and bringing interest or fun), emotion (e.g., increasing emotional readiness), and environment (e.g., eliminating negative surroundings). These motivational regulation strategies have been widely recognized for their roles in improved learning outcomes (Teng \& Zhang, 2016; Teng et al., 2020). For example, in their study of EFL learners' uses of motivational regulation strategies in a Chinese EFL course, Teng and colleagues (2020) found that students with higher writing abilities had better mastery and performance in self-communication, increased interest, and emotional control than those with lower writing abilities. Other researchers focused on learners' ability to recognize, regulate, and express emotions in accordance with different learning goals (e.g., Gibriel, 2019; Jang \& Rha, 2014). Gibriel (2019), for example, showed that highly anxious L2 learners used different writing strategies in EFL writing classes from the less anxious. Failure to use emotional control strategies led to negative attitudes toward L2 writing itself (Jang \& Rha, 2014).

\subsection{Roles of Social Context in Learning}

Greatly influenced by Vygotsky's (1978) sociocultural theory, studies on learner autonomy have highlighted the concrete and procedural effect of the social realm on cognitive development. This theory explicates that learning occurs through a learner's participation in a certain task or activity and continuous adaptation to the unfolding circumstances and activities (Vygotsky, 1978; Wertsch, 1991). While participating in those activities, learners can construct learning environments, tasks, identities, and context (Wertsch, 1991). Given the significance of the learners' own participation in learning processes and outcomes, L2 motivation is now considered a learner variable in constant interaction with learners' immediate context perceived as important including native English-speaking instructors, English as a second language (ESL) or EFL context, and online-learning program. For example, Nam (2011) showed that beginner-level English learners tend to be more anxious than intermediate-level learners in the classroom taught by a foreign instructor, a main factor creating an EFL context. Meanwhile, in her study of ESL speaking anxiety of English learners in America, Jo (2010) showed that these ESL learners' 
anxiety was only below than the median. They were also found to be more instrumentally motivated to learn English, i.e., for travel, making new friends, or prestigious jobs.

Another emerging contextual factor investigated in the studies of L2 learners' autonomy is online education. Since 2020, when the pandemic forced classrooms around the world to be completely online, some researchers have launched projects on its new position in education. M. Kim (2020) examined synchronous versus asynchronous online settings for their effectiveness on EFL writing and reported that appropriate use of both of these online environments is effective for writing classes. Atmojo and Nugroho (2020) surveyed $16 \mathrm{EFL}$ teachers working at Indonesian middle schools about the problems they faced while conducting online classes. The interaction between teachers and students was found to be increased in real-time, synchronous online classes compared to asynchronous online classes. For discussion and report assignments, by contrast, the students preferred asynchronous online classes. The diverse effects of the context should be visible when class contents taught through diverse online stations are relevant to learners' personal goals (Stanchevici \& Siczek, 2019). The effectiveness of the online learning context is thus dependent upon ample concerns with individual learners as well as technical support.

Finally, this study focuses on the policy of English-medium instruction (EMI) as a contextual factor of L2 learning. This policy has been adopted as a major strategy to implement the internationalization of Asian HE. It was considered effective, on the one hand, in creating a second language environment in foreign language societies, while culpable, on the other hand, in engendering global competitiveness and increasing the population of international members (E. G. Kim, Kweon, \& J. Kim, 2017). Despite its shortcomings, the significance of EMI in the globalized educational market can hardly been denied (E. G. Kim et al., 2017; J. Kim et al., 2018). EMI may be effective and successfully implemented, depending on both the local context and learning goals, For example, in a study of relationships between Korean EFL students' writing performances and perceptions of various learning contexts, J. Kim (2011) showed that the learning environment established by EMI was perceived as crucial in college EFL learners' learning experiences. Specifically, this contextual variable was found to be significantly interrelated with those learners' motivation to learn L2 writing.

The aforementioned studies show that, despite the wealth of research on L2 motivation and learning writing, research on the dynamic workings of motivational strategies in delivering locally bound constraints remain under-explored. Several scholars (e.g., Oxford, 2013; Oxford \& Amerstorfer, 2018; Teng et al., 2020; Zhang et al., 2019) have called for further studies which situates language learning strategies within a context-specific environment to promote validity to the field of research. Particularly, there is a lacuna in EFL research on motivational regulation in an online EFL writing class via Zoom. The current study thus investigates these motivational regulation strategies in an EFL writing 
course, with particular interest in context-specific factors, such as Zoom online learning, EMI, and native English-speaking instructors. As these localized factors have recently been adopted by a growing number of Korean universities and rigorously examined by some SLA researchers (e.g., J. Kim, 2011; J. Kim et al., 2018), this study will ultimately improve L2 educators' understanding of the ways in which EFL writing learners react to specific contextual constraints, develop L2 writing proficiency in an autonomous manner, and achieve their learning goals.

\section{METHODOLOGY}

\subsection{Research Questions}

This study adopts a mixed method to examine the relationships among EFL writing proficiency, motivational regulation strategies, and the underlying factors related to college EFL learners' strategies of choice. This research project has been guided by the following questions:

1. What are the differences in motivational regulation between high and low proficiency groups of college EFL learners taking writing course via Zoom?

2. To what extent do the high writing-proficiency students distinguish from the low writing-proficiency students in terms of their perceptions of context?

3. In what ways are these perceptions of contextual factors interrelated with their uses of the motivational regulation strategies?

\subsection{Context and Participants}

The study was conducted at a research-oriented South Korean university which has implemented a university-wide policy of EMI since 2009. The policy enforces the use of English in all subject courses as well as foreign language ones. Regardless of the subject, English is officially mandated for class interactions and tests, although the Korean language may be in use for extracurricular communication. Also significant to the context are synchronous online learning environments (i.e., Zoom) and native English-speaking instructors. Since 2020, the university set a synchronous online class via Zoom as the norm. Platforms like Zoom, according to Lowenthal, Borup, West, and Archambault (2020), create an environment most similar to traditional classroom teaching. According to the class management guidelines, asynchronous pre-recorded online materials are to be used only for exceptional cases. Zoom classes are also to be recorded and published on an asynchronous 
learning management system (LMS) for international students taking courses while residing in their countries.

Study participants comprised 173 local Korean undergraduate students enrolled in an English writing course. These students self-selected as participatory volunteers following an email concerning study information and a link to questionnaires. The participants were enrolled in one of the 11 sections taught by four native English-speaking instructors from Western English-majority countries. At the time of the research, these instructors had taught the course at least one semester through Zoom at the institution. For the homogeneity of the participants, 19 international students enrolled in the course were excluded from the current study. Those responses of the 154 Korean students (108 males and 46 females) were examined for the research questions. Most of the students indicated engineering as their majors, senior students being the largest in number (Table 1). Their levels were predetermined according to a placement test that all the freshmen were required to take immediately following official registration to the university. Consisting of TOEFL items, the test targeted to assess students' proficiency levels of English speaking and writing. The two levels of proficiency examined in this study represent beginner-high and intermediatelow (level 1) and intermediate-high and advanced-low (level 2).

\section{TABLE 1}

Participant Information $(N=154)$

\begin{tabular}{lc}
\hline \hline \multicolumn{1}{c}{ Participants } & $N(\%)$ \\
\hline Gender & \\
Male & $108(70 \%)$ \\
Female & $46(30)$ \\
English Ability & \\
Beginner-high Intermediate-low (level 1) & $41(27 \%)$ \\
Intermediate-high Advanced-low (level 2) & $113(73 \%)$ \\
Major & \\
Business management & $20(13 \%)$ \\
Engineering & $113(76 \%)$ \\
Pre-major (Freshmen) & $21(14 \%)$ \\
Academic year & \\
Freshmen & $21(14 \%)$ \\
Sophomore & $42(27 \%)$ \\
Junior & $36(23 \%)$ \\
Senior & $55(36 \%)$ \\
\hline
\end{tabular}

\subsection{Data Collection Procedure and Analyses}

This study was a part of a large project regarding EFL learners' motivational regulation and foreign language education reform in the post COVID-19 era. The dataset was constructed and analyzed using a mixed method. By incorporating qualitative and 
quantitative approaches, this method triangulates and validates the data, which provides a comprehensive picture of the issue under investigation (Creswell \& Plano Clark, 2018). For the quantitative part of the study, questionnaires of 41 items were constructed and administered to the participants. Consisting of three parts, the questionnaires included a brief description of the purpose of the survey and questions on the participants' demographic information ( 5 items), followed by the items on motivational regulation strategies ( 23 items). These items were constructed based on the previous research on motivational regulation (Dörnyei, 2001; Teng \& Zhang, 2016). The final part (13 items) was related specifically to major contextual factors under investigation: Native English-speaking instructors; onlineasynchronous; Zoom-synchronous; and EMI. These items came from previous research on effectiveness of online learning and roles of contexts in L2 learning (J. Kim, 2011; Wu \& Chen, 2017). Revised by the researchers, those items on the motivational regulation strategies and the contextual factors were presented on a five-point Likert scale (1-5), 1 corresponding to 'strongly disagree' and 5 to 'strongly agree'.

The questionnaires were administered three weeks before the end of semester. The quantitative data were analyzed, using the SPSS statistics program. We first selected the items for the relevant variables for each research question. The reliability estimates were then calculated as Cronbach's coefficient alpha scores on each motivational regulation strategy in addition to the major contextual variables (Table 2). The scores ranged from .511 (Context: Online-Asynchronous) to .889 (Motivational regulation: Feedback-Peers), which were considered acceptable for the further examination of the data. We then ran descriptive statistics in terms of means and standard deviation by the two writing proficiency groups (low versus high). The statistical significance of between-group differences by proficiency levels was tested through t-test statistics. The relationship between the choices of motivational regulation strategies and each of the contextual variables was calculated through Pearson correlation coefficient.

For the qualitative part of the study, four students from each proficiency group, were selected from the survey participants who responded positively to follow-up interviews. Out of eight who volunteered for the interviews, these four were available during the interview week. They were recruited through emails, and four of those were available. The questions mainly regarded their learning experiences through Zoom including processes while completing tasks, feedback response activities, and their views on EMI and foreign instructors. The interviews were conducted by one of the researchers in Korean. Each interview was conducted one-on-one for about 30 minutes. These audio-recorded interviews were transcribed verbatim and cross-referenced with the quantitative data. 
TABLE 2

The Reliability Estimates of Variables (Cronbach's coefficient alpha)

\begin{tabular}{|c|c|c|c|}
\hline & Variables (example item) & Item Number & Reliability \\
\hline \multirow{9}{*}{ 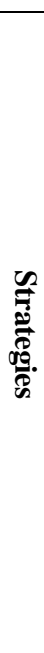 } & $\begin{array}{l}\text { Text Processing (\#6. When writing, I check organization and } \\
\text { logical coherence of ideas.) }\end{array}$ & $6,7,8$ & .641 \\
\hline & $\begin{array}{l}\text { Idea Planning (\#11. Before writing, I think about the core } \\
\text { elements of a good composition I have learned to help me plan.) }\end{array}$ & $9,10,11$ & .513 \\
\hline & $\begin{array}{l}\text { Goal-Oriented Monitoring/ Evaluating (\#12. I monitor my } \\
\text { learning process in writing courses.) }\end{array}$ & 12,13 & .777 \\
\hline & $\begin{array}{l}\text { Feedback-Peers (\#15. Feedback from my peers help to complete } \\
\text { a writing.) }\end{array}$ & $14,15,16$ & .889 \\
\hline & $\begin{array}{l}\text { Feedback-Instructors (\#17. I try to improve my English writing } \\
\text { based on instructor's feedback.) }\end{array}$ & 17,18 & .755 \\
\hline & $\begin{array}{l}\text { Interest Enhancement (\#21. I connect the writing task with my } \\
\text { real life to intrigue me.) }\end{array}$ & $19,20,21$ & .737 \\
\hline & $\begin{array}{l}\text { Motivational Self-Talk (\#22. I tell myself that I need to keep } \\
\text { studying to improve my writing competence.) }\end{array}$ & 22,23 & .566 \\
\hline & $\begin{array}{l}\text { Emotional Control (\#24. I try not to get anxious when answering } \\
\text { questions in this course.) }\end{array}$ & 24,25 & .536 \\
\hline & $\begin{array}{l}\text { Environment Structuring (\#27. I've changed my surrounding so } \\
\text { that it is easy to concentrate on writing) }\end{array}$ & $26,27,28$ & .725 \\
\hline \multirow{4}{*}{ 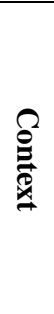 } & $\begin{array}{l}\text { Native English-speaking Instructors (\#33. Learning English } \\
\text { writing from a native English speaker has helped me improve my } \\
\text { writing.) }\end{array}$ & 29 , & .7 \\
\hline & $\begin{array}{l}\text { Online-Asynchronous (\#32. I think non-real-time online } \\
\text { materials can be more effective in learning English writing.) }\end{array}$ & $30,31,32$ & .511 \\
\hline & $\begin{array}{l}\text { Zoom-Synchronous (\#38. The class via Zoom is effective in } \\
\text { learning English writing.) }\end{array}$ & $36,37,38$ & .563 \\
\hline & $\begin{array}{l}\text { EMI at the Institution (\#39. It is important to become a good } \\
\text { English writer in an EMI context) }\end{array}$ & $35,39,40,41$ & .603 \\
\hline
\end{tabular}

\section{RESULTS}

\subsection{Motivational Regulation Strategies by Proficiency Levels}

Overall, the participants responded to their uses of motivational regulation strategies higher than the median, 3. In the descriptive statistics, of those nine strategies, the mean score for the text processing was the highest, 4.25 . This finding shows that the students were explicitly aware of the EFL-specific writing processes, ranging from word- and sentencelevel grammar to paragraph-level idea presentation, or the organization of a short essay. As seen in Table 3, the mean score for the strategy of motivational self-talk was high, 4.23, which highlights that the participants particularly tried to relate writing tasks with their own pragmatic purposes. In contrast, the participants neither engaged in feedback from their peers, nor valued its effectiveness in improving writing, as shown in the mean score falling lowest, 
3.17. Their effort to regulate emotion while learning EFL writing (emotional control) was not high, remaining slightly above median, 3.6.

TABLE 3

Motivational Regulation Strategies

\begin{tabular}{lcccc}
\hline \hline \multicolumn{1}{c}{ Strategies } & Minimum & Maximum & Mean & SD \\
\hline Text Processing & 2.00 & 5.00 & 4.25 & .669 \\
Idea Planning & 2.00 & 5.00 & 4.17 & .721 \\
Goal-Oriented Monitoring/ & 1.00 & 5.00 & 3.73 & .943 \\
Evaluating & & & & \\
Feedback -peers & 1.00 & 5.00 & 3.17 & .954 \\
Feedback -instructors & 1.50 & 5.00 & 4.09 & .839 \\
Interest Enhancement & 1.00 & 5.00 & 4.06 & .853 \\
Motivational Self-Talk & 2.33 & 5.00 & 4.23 & .640 \\
Emotional Control & 1.50 & 5.00 & 3.60 & .828 \\
Environment Structuring & 1.50 & 5.00 & 3.83 & .856 \\
\hline
\end{tabular}

Presumably, this result is linked to the curricular goals highly centered on a process approach to writing, advancing from brainstorming of ideas, developing topic sentences, towards the completion of 4-5 paragraph essay. By the time of the research, the participating students had been not only taught of these specific writing topics, but also practiced these through class activities and two small paragraph-level writing assignments. As significant as this instructional approach is authenticity of materials tailored to the institution. The writing topics included in the curriculum included authentic science and engineering issues at large, e.g., 'importance of (students' major) in the post-pandemic era.' This design of the course therefore explicates the high mean scores on the students' uses of 'text processing' and 'motivational self-talk' shown in the results.

These uses of the nine strategies were subsequently compared between the students' two English proficiency levels, high versus low. As seen in Table 4, the high proficiency group showed higher mean scores on most of the strategies. This result indicates that those with a higher level of EFL proficiency are able to use different strategies to regulate their motivation to learn English writing. On the subsequent t-test procedure (Levene's Test for Equality of Variances), the between-group difference was significant only in their uses of instructor's feedback (F-I) $(p<.05)$; none of the other between-group comparisons were found statistically significant. The students' higher level of proficiency can be a clear indicator of their responsiveness to instructors' feedback. However, they showed contradictory attitudes towards adopting feedback, neither engaging in feedback from their peers, nor valuing its effectiveness in improving writing, as shown in the mean score falling the lowest, 3.17. On the other hand, the low proficiency group was found to be in more need for peer feedback in a team activity, while being lukewarm about accommodating the feedback from their instructors to their writing activities. 
TABLE 4

Difference in Perceptions of Motivational Regulation Strategies

\begin{tabular}{|c|c|c|c|c|c|c|}
\hline Strategies & Level $(N)$ & Mean & $\overline{S S D}$ & 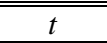 & $\frac{d f}{d f}$ & Sig. \\
\hline \multirow[t]{2}{*}{$\mathrm{TP}$} & Low (41) & 4.13 & 0.596 & -1.307 & 152 & .193 \\
\hline & High (113) & 4.29 & 0.691 & & & \\
\hline \multirow[t]{2}{*}{ IP } & Low (41) & 4.15 & 0.735 & -0.232 & 152 & .817 \\
\hline & High (113) & 4.18 & 0.719 & & & \\
\hline \multirow[t]{2}{*}{ GME } & Low (41) & 3.60 & 1.038 & -1.054 & 152 & .293 \\
\hline & High (113) & 3.78 & 0.906 & & & \\
\hline \multirow[t]{2}{*}{ F-P } & Low (41) & 3.20 & 1.133 & 0.303 & 152 & .762 \\
\hline & High (113) & 3.14 & 1.078 & & & \\
\hline \multirow[t]{2}{*}{ F-I } & Low (41) & 3.80 & 0.957 & $-2.661 *$ & 152 & .042 \\
\hline & High (113) & 4.25 & 0.785 & & & \\
\hline \multirow[t]{2}{*}{$\mathrm{IE}$} & Low (41) & 3.91 & 1.042 & -1.234 & 152 & .219 \\
\hline & High (113) & 4.11 & 0.772 & & & \\
\hline \multirow[t]{2}{*}{ MST } & Low (41) & 4.11 & 0.729 & -1.329 & 152 & .186 \\
\hline & High (113) & 4.27 & 0.602 & & & \\
\hline \multirow[t]{2}{*}{$\mathrm{EC}$} & Low (41) & 3.60 & 0.872 & -0.143 & 152 & .786 \\
\hline & High (113) & 3.65 & 0.815 & & & \\
\hline \multirow[t]{2}{*}{$\mathrm{ES}$} & Low (41) & 3.77 & 0.929 & -0.548 & 152 & .585 \\
\hline & High (113) & 3.85 & 0.831 & & & \\
\hline
\end{tabular}

* The mean difference is significant at the 0.05 level.

Notes. TP: Text Processing; IP: Idea Planning: GME Goal-Oriented Monitoring/ Evaluating; F-P: Feedback - Peers; F-I: Feedback - Instructors; IE: Interest Enhancement; MST: Motivational SelfTalk; EC: Emotional Control; ES: Environment Structuring

Regarding learning writing via Zoom, interviewees commented on different strategies they used to maintain their motivation. In the following two excerpts, two interviewees projected two contradictory perspectives into handling their learning environment, or the strategy of environment structuring ${ }^{1}$ :

"There are things around [my laptop] when I have to be focused on class, like internet and all the SNS things (laughing) Sometimes I miss a chance to participate in class doing Katok [Kakao Talk messenger] on the screen. So I should say that I get frequently distracted during the Zoom class." (Int02: Sophomore; Proficiency-Low)

"There are many convenient stuffs. During class, I can search internet and get information real-time, like some English expressions or words. I can copy and paste them into the class online document." (Int03: Senior; ProficiencyHigh)

\footnotetext{
${ }^{1}$ Each excerpt is labeled to signify distinct students in terms of their year of study and level of English proficiency.
} 
These excerpts elucidate that the Zoom learning environment requires EFL learners' strategic control of (non)-class related online materials, i.e., environment structuring. Interestingly, this environment was strategically restructured for the efficiency of text production for the student from the high proficiency group (Int03). It was, however, a challenge for the other with a lower level of proficiency (Int02). Monitoring and structuring this L2 learning environment were thus critical for the learning processes. The analysis of these context-related factors is presented in the following section.

\subsection{Perceptions of Context by Proficiency Levels}

The second research question regards the ways in which the students taking the EFL writing course via Zoom perceive the context-specific factors by their proficiency levels. We explored four factors, foreign instructors, asynchronous online learning, synchronous Zoom learning, and the EMI-enforced campus, all of which were specific to the FL learning context of the HE institution. The results revealed a clear discrepancy in the perceived effectiveness of those factors to learning EFL writing (Table 5). The factor of foreign instructors gained the highest mean score, 4.18, while the other contextual factors staying in the 3's. The mean score for the synchronous Zoom learning was the lowest of all, 3.61.

\section{TABLE 5}

Perceptions of Context

\begin{tabular}{lcccc}
\hline \multicolumn{1}{c}{ Contextual factors } & Minimum & Maximum & Mean & SD \\
\hline Foreign instructors & 2.00 & 5.00 & 4.18 & .770 \\
Online-Asynchronous & 2.50 & 5.00 & 3.73 & .577 \\
Zoom-Synchronous & 1.67 & 5.00 & 3.61 & .698 \\
EMI at the institution & 1.00 & 5.00 & 3.89 & .837 \\
\hline
\end{tabular}

Given the variance of the mean scores, we further examined whether the students' levels of proficiency contributed to the differences in the ways they perceived these factors. On the $t$-test procedure (Levene's Test for Equality of Variances), between group differences were found significant for Zoom $(p<.05)$ and EMI $(p<.01)$ (Table 6). For both factors, those with a higher level of English proficiency obtained significantly higher mean scores than the other group. Intriguingly, this low proficiency group showed the higher mean score on asynchronous online learning than the high proficiency group. Although statistically insignificant, this difference indicates that the low proficiency group tends to be in favor of an asynchronous online learning context. 
TABLE 6

Difference in Perceptions of Context by Proficiency Levels

\begin{tabular}{lcccccc}
\hline \hline \multicolumn{1}{c}{ Contextual Factors } & Level $(N)$ & Mean & $S D$ & $t$ & $d f$ & Sig. \\
\hline \multirow{2}{*}{ Foreign instructors } & Low (41) & 4.07 & 0.786 & \multirow{2}{*}{-1.156} & \multirow{2}{*}{152} & \multirow{2}{*}{0.249} \\
Online-asynchronous & High (113) & 4.23 & 0.763 & & & \\
& Low (41) & 3.82 & 0.557 & \multirow{2}{*}{1.224} & \multirow{2}{*}{152} & \multirow{2}{*}{0.223} \\
& High (113) & 3.69 & 0.582 & & & \\
Zoom-synchronous & Low (41) & 3.43 & 0.746 & $-1.938^{*}$ & \multirow{2}{*}{152} & \multirow{2}{*}{0.049} \\
& High (113) & 3.68 & 0.672 & & & \\
EMI & Low (41) & 3.59 & 1.014 & \multirow{2}{*}{$2.994^{* *}$} & \multirow{2}{*}{152} & \multirow{2}{*}{0.008} \\
& High (113) & 4.00 & 0.742 & & & \\
\hline
\end{tabular}

* The mean difference is significant at the 0.05 level.

** The mean difference is significant at the 0.01 level.

Notably, the EMI context of the university contributes to the overt difference between the two levels $(p<.01)$. The high proficiency group weighed to be significant the positioning of the instructional language policy not only for the university's internationalization; but they also supported it for learning EFL writing. This positivity towards EMI is vividly described in the following interview excerpt:

"I've been under constant pressure to improve English because of this $100 \%$ English lecture thing. It was very very hard in my freshman year. But I've seen my seniors doing a great job abroad, like in an American university, a research lab or a graduate school. I'm not sure if I want to go abroad after graduation yet. But there might be opportunities. I'd like to keep the door open. Then, after all, EMI should be good.” (Int04: Sophomore; Proficiency-High)

The interviewees evaluated Zoom differently according to different aspects of participation in class. As shown in one interviewee's comment in the following excerpt, it was positively viewed in terms of the convenience that an online context may offer, such as class attendance. Its function to foster interaction, however, was not found to be effective:

'I think students' attendance is better because it's Zoom. But it's very difficult to get participation scores on Zoom. We should click on 'raise hand' to say something. It's annoying to compete to just say something." (Int01: Freshmen; Proficiency-Low)

The findings hint at the ways these participants interpret and cope with the relevant contextual factors to learn EFL writing. It is noteworthy that the participants' proficiency 
levels are indicative of the differences in the ways they evaluate the class learning platform, Zoom and the university's major policy for internationalization, EMI. These emerging contextual factors are thus utterly important to creating a favorable learning environment for the EFL writing course.

\subsection{Relationships between Context and Motivational Regulation}

To address the final research question as to the relationship between students' choices of motivational regulation strategies and their perceptions of the relevant contextual factors, we calculated Pearson's correlation coefficients between the pairs of each strategy and contextual factor. Prior to this procedure, we investigated the relationships among the strategies. Across most of the paired strategies, the correlation coefficients were found significant. Although not surprising, these strong interrelationships between strategies corroborate roles of each of the strategies in learning EFL writing. It is also interesting to note that the students' strategic uses of peer feedback correlated significantly with their perspectives of the instructors' feedback (Pearson $r=.546^{* *}, p<.01$ ). Despite the discrepancy of the students' uses of these two strategies by proficiency levels, those using one of these tended to use the other more. Likewise, the relationships between the contextual factors were found to be mostly significant as shown in the examination of correlation coefficients (Table 7). The students' perceptions of one of the two online learning contexts, asynchronous LMS versus synchronous Zoom, had no discernable relationship with the other.

The results also clearly show a significant relationship between the students' choices of motivational regulation strategies and their perceptions of the context-dependent factors. In all these trends, some of the relationships are noteworthy. First, students' strategic uses of instructors' feedback (F-I) correlated significantly with students' views of the foreign instructor, a major contextual factor. Thus, the more they appreciated the nativeness of the instructor, the more they tended to use the feedback from the instructor as a way to regulate their motivation to learn EFL writing, or vice versa (Pearson $r=.663^{* *}, p<.01$ ). This strategic choice of instructor feedback was also positively related with their perception of the university's instructional language policy, EMI (Pearson $r=.421^{* *}, p<.01$ ). This positive relationship is of importance; learning EFL writing is not separable from the explicit role of the English language in the institution. More specifically, the students' perspectives of this policy are closely related with their engagement in the native English-speaking instructor's feedback.

Finally, the statistical analysis disclosed a negative relationship between the uses of peer feedback and the perceived importance of an asynchronous learning context (Pearson $r=$ -.034). This negative relationship is not to be ignored considering the mean score for the use 
of peer feedback being the lowest among all the strategies. They found in favor of LMS, an asynchronous learning context, while being lukewarm about the feedback given by their peers. This negative relationship was also commented by an interviewee:

"I guess I'd like to have non-real time classes. I can be better focused if the classes were non-real time. I won't be less anxious when I don't have to work in teams. We write our texts in Google doc and discuss them in [Zoom] breakout rooms. Sometimes these work. But most of the times, I find myself a little anxious for time and the outcome. Some don't really talk, and we are not sure about what to do.” (Int02: Sophomore; Proficiency-Low)

Two other interviewees with a higher level of the proficiency commented on using instructor's feedback in relation to having classes with a native English-speaking instructor and an EMI policy, two major contextual factors.

"We have many real-time activities in this class, and we get real-time feedback from the instructors. It's like a speaking class, English conversation, when it's in fact a writing class. Since the instructor is a native speaker [of English], we can improve our speaking skill as well as writing. Like catching two rabbits, isn't it? (laughing)" (Int04: Sophomore; Proficiency-High)

"I think this $100 \%$ English lecture is an important feature of the university. Globalization is power, I believe. It's important for my personal goal, too. Most of us[seniors] are planning to go to a graduate school, here in Korea or in other countries, where I'm sure I'll have to work with foreign nationals like post-doctoral researchers. There's also pressure for writing many research papers for publication too. It's crucial to improve my English writing at the moment and in this class, I find my instructor's tips quite useful. I wish I had practiced on those before the military service. I would be much better prepared for my future (laughing).” (Int03: Senior; Proficiency-High)

These two interview excerpts above corroborate the web of relationships among strategic choices of using instructor's feedback, the nativeness of instructors, and the university's instructional language policy. It deserves to be noted that the relationships are legitimized by the participants' conscious effort to construe their personal interest (e.g., developing an English-speaking skill) or goals (e.g., a career plan) in the learning context. The work of relationships is thus dynamic, dependent upon the extent to which the learners exert autonomy in regulating motivation. 


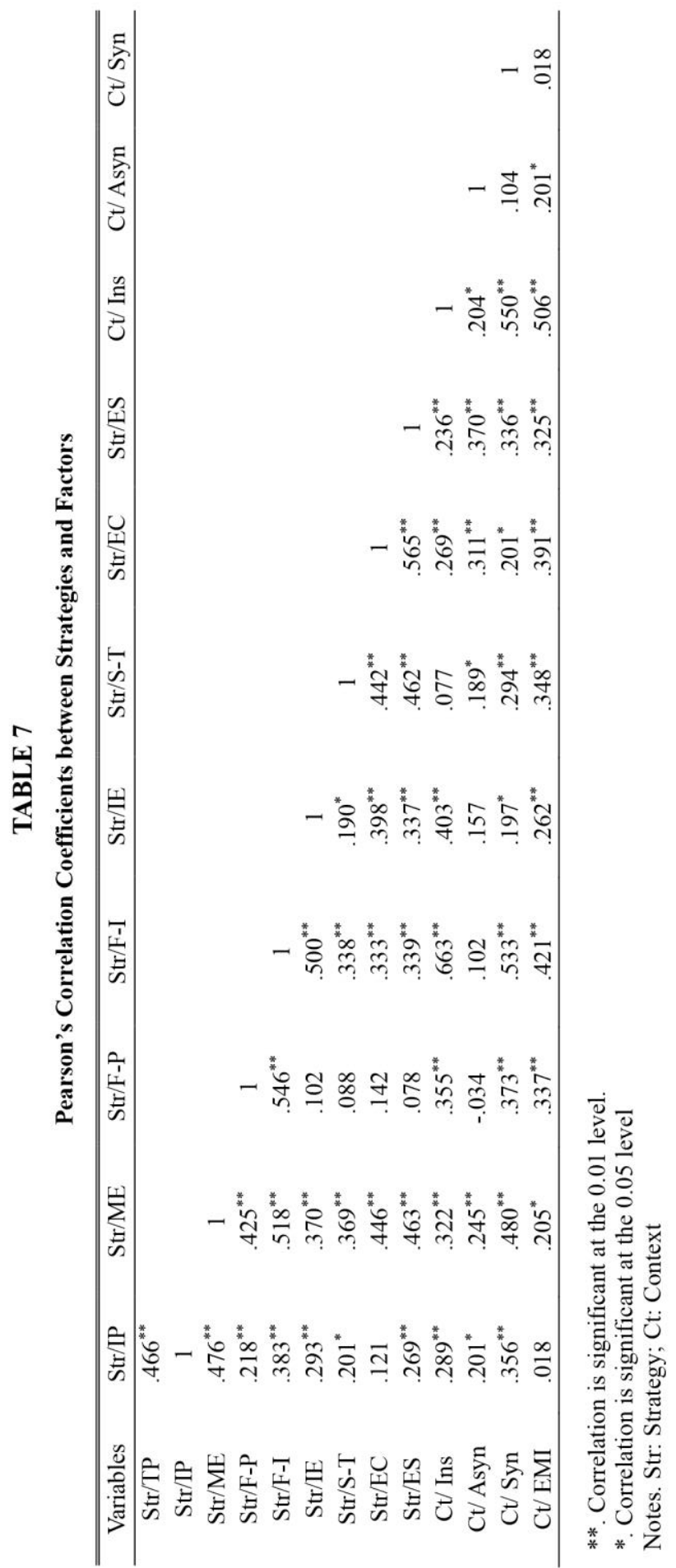

Motivational Regulation for Learning English Writing Through Zoom in an English-Medium Instruction Context 


\section{DISCUSSION AND CONCLUSION}

This study investigated Korean EFL learners' self-regulation in the context of a synchronous online EFL writing course. Grounded in the hypothesis that the innovations forced on institutions by the pandemic will have a lasting effect on education (Daniel, 2020), it sought to disclose the ways in which the online learning environment, matched with other imminent context-bound factors such as foreign instructors and EMI, contribute to student use of motivational regulation strategies. The findings demonstrate that usage of these strategies is affected by the pedagogical context of the Korean university. A few dominant trends of relationships merit further discussion. First, it is of paramount importance to note that EFL students' perceptions of the roles of native-English instructors greatly impact their choices and uses of instructor feedback. This interplay between context and motivational regulation strategy suggests a definite contribution of EFL instructors to the ways in which learners integrate feedback into EFL writing. More importantly, the significant differences in the choices of strategies by student proficiency require explicit recognition by writing instructors and program designers alike. When those with lower levels of English proficiency obtain support tailored to their needs, they are more likely to be responsive to instructor feedback and to self-regulate their motivation towards writing improvement.

Another point of discussion concerns the authenticity of the EFL learning context at large, which interacts with motivational regulation. In light of the sociocultural perspective, motivational regulation is culturally dependent and there is no universal motivational strategy that can be applied to all EFL classrooms across all cultures (Teng \& Zhang, 2016; Wong, 2014). The present study showcases the significant, positive relationship between the use of instructors' feedback and the views of EMI that these learners may bring to a writing course conducted via Zoom. Apparently, learning EFL writing is inseparable from the explicit role of the English language at large in an institution. As shown in the present study, the policy has a discernable effect on EFL writing learners' motivational regulatione.g., the strategy of incorporating instructors' feedback into subsequent writing activities such as revision. More importantly, given the significantly positive perspective of this university-wide policy by students of higher proficiency, the current study reaffirms and further highlights that an educational context with EMI should be provided with a deliberately designed curriculum for different students' English proficiency levels.

The final point of discussion rests on the effectiveness of the platform of Zoom to learning EFL writing. A recent contrastive study on synchronous versus online platforms suggests that synchronous online platform like Zoom can create an environment most similar to traditional classroom teaching (Lowenthal et al., 2020). Asynchronous prerecorded online materials have been less appreciated and are generally ill-advised. However, the participants in the present study valued Zoom the least of all the contextual factors. 
Their perspectives were significantly divided by their levels of English proficiency; the higher the proficiency, the better Zoom was appreciated, and vice versa. This finding questions the secure positioning of Zoom as an effective instructional platform for EFL writing. As indicated in the interviews, Zoom has been evaluated differently according to different aspects of participation in class. While it was positively viewed in terms of convenience (e.g., log-in attendance), class interaction was significantly limited and ineffective.

These findings suggest two channels through which language educators may overcome these limitations. One would promote systematic strategy-based writing instruction (Teng et al., 2020). The participants in this study, regardless of their writing proficiency levels, were found to be lukewarm about using motivational regulation strategies other than text processing clearly noted in the syllabus and lessons. As Teng and colleagues (2020) claim, these strategies should be instructed in a purposeful and systematic manner for EFL learners; their strategic choices should be conscious, goal-orientated and task-focused. Undoubtedly, these strategies should also be tailored to the new learning context that Zoom offers (e.g., an environment-structuring strategy specific to an online learning environment, as suggested by two interviewees in this study). The other channel would cater to different proficiency levels in an EFL writing course taught via Zoom. As some recent research suggests (e.g., Daniel, 2020; Hsiao \& Huang, 2012; Lowenthal et al., 2020), those with a lower level of English proficiency may supplement Zoom lessons with asynchronous online materials available in LMS. Their preference for peer feedback and entailing frustration for a lack of class participation on Zoom may also be alleviated on the asynchronous activities - e.g., video feedback by instructors (V. Kim, 2018) or email peer feedback activities. They may earn more time to prepare their responses to instructional materials and gain an opportunity for participation (Hsiao \& Huang, 2012; V. Kim, 2018).

Despite the immediate practical implications to EFL writing education via Zoom, the current study is not without limitations due to the design of the research. The study was conducted at a single university in Korea and its implications should be applied to other contexts in a cautious manner. It also relied on students' self-reporting during one semester of a Zoom EFL writing course with no evaluative comments from their instructors. The instructors' views on or orientations to foster students' motivational regulation strategies should have substantial effect on crafting their students' learning experiences (Wong, 2014). However, these were beyond the scope of the current study. Further studies may overcome these limitations and expand to the changes in students' choices of strategies depending on online stations. This further exploration should provide a comprehensive view on where support is needed in the post-COVID-19 era of EFL education. 
Applicable level: Tertiary

\section{REFERENCES}

Atmojo, A. E. P., \& Nugroho, A. (2020). EFL classes must go online! Teaching activities and challenges during COVID-19 pandemic in Indonesia. Register Journal, 13(1), 4976.

Bruning, R., \& Horn, C. (2000). Developing motivation to write. Educational Psychologist, 35(1), 25-37.

Creswell, J. W., \& Plano Clark, V. L. P. (2018). Designing and conducting mixed methods research (3rd ed.). London, UK: Sage.

Csizér, K., \& Tankó, G. (2017). English majors' self-regulatory control strategy use in academic writing and its relation to L2 motivation. Applied Linguistics, 38(3), 386404.

Daniel, S. J. (2020). Education and the COVID-19 pandemic. Prospects, 49(1), 91-96.

Dörnyei, Z. (2001). Motivation strategies in the language classroom. Cambridge, UK: Cambridge University Press.

Dörnyei, Z., \& Ushioda, E. (2011). Teaching and researching motivation. London, UK: Routledge.

Gibriel, M. (2019). Investigating writing strategies, writing anxiety, and their effects on writing achievement: A mixed method design. The Journal of Asia TEFL, 16(1), 429436.

Hsiao, E. L., \& Huang, X. (2012). Synchronous and asynchronous communication in an online environment: Faculty experiences and perceptions. Quarterly Review of Distance Education, 13(1), 15-30.

Jang, J., \& Rha, K-H. (2014). An analysis on the effect of Korean English learners' anxiety on their writing performance. Studies in Linguistics, 30, 209-228.

Jo, M. (2010). An Investigation in variables of English speaking anxiety levels of ESL learners in America. Studies in English Language \& Literature, 36(4), 289-308.

Jung, H. (2020). College students' satisfaction with the overall implement of online classes and testing during the Corona 19 pandemic. Multimedia-Assisted Language Learning, 23(3), 392-412.

Kim, E. G., Kweon, S-O., \& Kim, J. (2017). Korean engineering students' perceptions of English-medium instruction (EMI) and L1 use in EMI classes. Journal of Multilingual and Multicultural Development, 38(2), 130-145. 
Kim, J. (2011). Relationships among motivation, contextual factors and achievement in onoffline blended English writing class. English Language \& Literature Teaching, 17(4), 97-122.

Kim, J., Kim, E. G., \& Kweon, S-O. (2018). Challenges in implementing English-medium instruction: Perspectives of humanities and social sciences professors teaching engineering students. English for Specific Purposes, 51, 111-123.

Kim, M. (2020). We want more interaction: Learners' viewpoints on the implementation of online university English classes. Journal of the Korea English Education Society, 19(4), 67-87.

Kim, V. (2018). Technology-enhanced feedback on student writing in the English-medium instruction classroom. English Teaching, 73(4), 29-53.

Korea Education Development Institute. (2020). A qualitative study of experiences of the students placed in disadvantageous environment during COVID-19 (RR 2020-23). Retrieved on April 01, 2021, from https://www.kedi.re.kr/khome/main/research/selectPubForm.do?plNum0=14114

Lee, D. J., \& Kim, M. (2020). University students' perceptions on the practices of online learning in the COVID-19 situation and future directions. Multimedia-Assisted Language Learning, 23(3), 1-20.

Lowenthal, P., Borup, J., West, R., \& Archambault, L. (2020). Thinking beyond Zoom: Using asynchronous video to maintain connection and engagement during the COVID-19 pandemic. Journal of Technology and Teacher Education, 28(2), 383-391.

Marcus, J. (2020). For some colleges, COVID-19 'accelerated innovation' in how to adapt. Retrived on March 13, 2021, from https://www.pbs.org/newshour/education/for-some-colleges-covid-19-acceleratedinnovation-in-how-to-adapt

Nam, J. (2011). Correlational study on English learners' motivation, anxiety, WTC and their English achievement scores in native teachers' classes. English Language \& Literature Teaching, 17(2), 139-160.

Noels, K., Pelletier, L., \& Vallerand, R. (2000). Why are you learning a second language? Motivation orientations and self-determination theory. Language Learning, 50(1), 57-85.

Oxford, R. L. (2013). Teaching and researching language learning strategies (2nd ed.). Harlow, UK: Pearson.

Oxford, R. L., \& Amerstorfer, C. M. (Eds.). (2018). Language learning strategies and individual learner characteristics: Situating strategy use in diverse contexts. London, UK: Bloomsbury.

Park, E. (2020). Perception of learner anxiety towards online college English classes during COVID-19. Multimedia-Assisted Language Learning, 23(3), 320-338. 
Stanchevici, D., \& Siczek, M. (2019). Performance, interaction, and satisfaction of graduate EAP students in a face-to-face and an online class: A comparative analysis. TESL Canada Journal, 36(3), 132-153.

Tang, R. (2012). The issues and challenges facing academic writers from ESL/EFL contexts: An overview. In R. Tang (Ed.), Academic writing in a second or foreign language: Issues and challenges facing ESL/EFL academic writers in higher education contexts (pp. 1-18). London, UK: Continuum.

Teng, L. S., Yuan, R., E., \& Sun, P. P. (2020). A mixed-methods approach to investigating motivational regulation strategies and writing proficiency in English as a foreign language contexts. System, 88, 102182.

Teng, L. S., \& Zhang, L. J. (2016). A questionnaire-based validation of multidimensional models of self-regulated learning strategies. Modern Language Journal, 100(3), 674701.

Vandergrift, L. (2005). Relationships among motivation orientations, metacognitive awareness and proficiency in L2 Listening. Applied Linguistics, 26(1), 70-89.

Vygotsky, L. S. (1978). Mind in society: The development of higher psychological processes. Cambridge, MA: Harvard University Press.

Wertsch, J. V. (1991). Voices of the mind: A sociocultural approach to mediated action. Cambridge, MA: Harvard University Press.

Wong, M. H. (2014). An investigation of strategies for student motivation in the Chinese EFL context. Innovation in Language Learning and Teaching, 8(2), 132-154.

Wu, B., \& Chen, X. (2017). Continuance intention to use MOOCs: Integrating the technology acceptance model (TAM) and task technology fit (TTF) model. Computers in Human Behavior, 67, 221-232.

Zhang, Y., \& Guo, H. (2012). A study of English writing and domain-specific motivationand self-efficacy of Chinese EFL learners. Journal of Pan-Pacific Association of Applied Linguistics, 16(2), 101-121.

Zhang, L. J., Thomas, N., \& Qin, T. L. (2019). Language learning strategy research in system: Looking back and looking forward. System, 84, 87-92.

Zimmerman, B. J. (2011). Motivational sources and outcomes of self-regulated learning and performance. In B. J. Zimmerman \& D. H. Schunk (Eds.), Handbook of selfregulation of learning and performance (pp. 49-64). New York, NY: Routledge. 